\title{
Active Magnetic Bearing system design featuring a Predictive current control
}

\author{
L. Papini, L. Tarisciotti, A. Costabeber, C. Gerada, P. Wheeler \\ Power Electronics, Machine and Control (PEMC) \\ University of Nottingham \\ Nottingham, UK \\ luca.papini@nottingham.ac.uk
}

\begin{abstract}
Active Magnetic Bearing (AMB) technology is becoming attractive for several reasons such as high speed operations, high reliability and vibrations exemption. Moreover, AMB can behave as active vibration dampers and provide a realtime control of the shaft. For all these advantages, AMBs are particularly attractive for high power - high speed applications. These desirable features come at the cost of an increased complexity of the system, which now includes a power electronic converter and a control system dedicated to the AMBs. This paper focus on the overall system design, from the AMB design, to the power electronic converter design and control, for an AMB featuring Wheatstone bridge winding configuration. The magnetic design has been developed analytically and validated by means of Finite Elements simulation, to generate up to $2 \mathrm{kN}$ of axial forces. The power conversion system is based on three full bridges, one to magnetize the bearing and two to control the axial forces independently on the $x$ and $y$ axes. In order to achieve high bandwidth current control able to generate the desired orthogonal forces, a predictive control strategy has been proposed, for the several advantages it can provides such as fast dynamic response, no need of modulation, easy inclusion of nonlinearities and constraints of the system, possibility of incorporating nested control loops in only one loop and the flexibility to include other system requirements in the controller. The control system has been validated in Matlab/PLECS simulation, including the effect of parameters mismatches in the coils.
\end{abstract}

Keywords-Active Magnetic Bearing, Predictive Control

\section{INTRODUCTION}

High speed applications and direct drive systems are gaining importance in industry and they are subject of extensive research. The maximum speed is mainly limited by the mechanical properties of materials, thermal issues and bearings limitations. Active Magnetic Bearings (AMB) technology has been available since the late seventies, mainly for high-end aerospace applications. The interest in the application of AMBs to a broader range of industrial products has recently increased due to the higher availability and lower cost of enabling technologies such as power electronics and control hardware. In fact, AMBs are becoming a valid alternative to standard rollbearing for rotating machines [1], reducing losses and achieving a full active rotor-dynamic control of the system. AMB technology presents several advantages: they can operate at very high speed with minimum loss and no mechanical wear and, due to the absence of friction, they are highly reliable and exempt from vibrations. In addition to these general features, they can act as dampers of other sources of vibration and the advanced position control system can provide a full real-time control of the shaft operating conditions. For all these advantages, AMBs are particularly attractive for high power as well as high speed applications [2].

Different magnetic bearing topologies in combination with their control strategy have been proposed in literature to reduce the position stiffness [3], to improve the force density, reduce losses [4] and improve dynamic performances. The operative principle of AMBs is based on the flux density unbalance in the main airgap, which leads to force acting on the rotor element. These flux density unbalances, hence forces, are generated by actively controlling the current supplied to the AMBs power coils. The coil arrangement and control system adopted are constantly under study as they play a fundamental role in the performances of the system. A variety of coil number and arrangement can be found in literature exploiting the capabilities of three-phase systems with respect the single phase ones. In this work, the Wheatstone Bridge (WB) configuration for the AMBs power coil is considered [5]. A wide range of control techniques have been proposed and investigated with the aim to minimize power dissipation [6], improve dynamic response [7] or increase robustness against unknown parameters or disturbances [8].

In order to control the coils currents, a power conversion system is required. In this work such system is realized using a six leg voltage source converter. The converter is capable of controlling the biasing magnetising flux density in the AMB through a DC current, identical in every coil, and control the rotor position over the $x$ and $y$ axes, by means of a current unbalance in the single AMB coils. However, since the six converter legs are connected to the same DC-Link and not isolated from the AMB coils, undesired circulating current are present and have to be suppressed by the current control.

The capability of controlling the coils current with a wide bandwidth is a crucial requirement, as it directly impacts the dynamic performances of the AMB. For such system, Model Predictive Control (MPC) represents an attractive solution, due to its inherently fast dynamic response, no need of modulation, easy inclusion of nonlinearities and constraints of the system, possibility of incorporating nested control loops in only one loop and the flexibility to include other system requirements in the controller [9]-[13]. MPC considers a model of the system in order to predict its future behaviour over a specific time horizon. On the basis of this model, MPC solves an optimization problem where a sequence of future actuations is obtained by minimizing a cost function which represents the desired behaviour of the system. The best performing actuation is then applied and all the calculations are repeated every sample period. Since switching power converters are systems with a finite number of states, given by the possible combinations of the state of the switching 
devices, the MPC optimization problem can be simplified and reduced to the prediction of the behaviour of the system for each of the possible states. Each prediction is evaluated using the cost function and the state that minimizes it, is selected [12]. This is an approach which has been successfully applied for the current control in three-phase inverters [10], [14], [15], Cascaded HBridge converters [11], [16] and Matrix converters [17], [18], as well as power control in an Active Front-End rectifier [10], [19], and torque and flux control of an induction machine [20], [21].

\section{ACTIVE MAGNETIC BEARING DESIGN AND MODELLING}

The AMBs schematic considered in this analysis is shown in Fig. 1, where the power coils are highlighted in red and in blue for the $x$-axis and the $y$-axis control respectively. A 2 axis control, 4 pole field active magnetic bearing is considered. In this configuration the power coils around each tooth are divided in two identical parts. These windings, together with the one on the opposite tooth are arranged to form a Wheatstone bridge configuration. The design is carried out to allow a force generation of $2 \mathrm{kN}$ for each axis. A DC-bias field is generated by imposing a DC current in the power winding in order to store magnetic energy in the bearing. A disturbance causing a rotor position displacement from the centred condition generates an unbalance in the air gap magnetic field that can be compensated by unbalancing the DC current in the power coils and, therefore, generating the required balancing force.

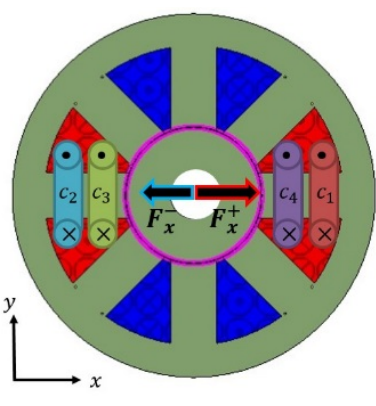

(a)

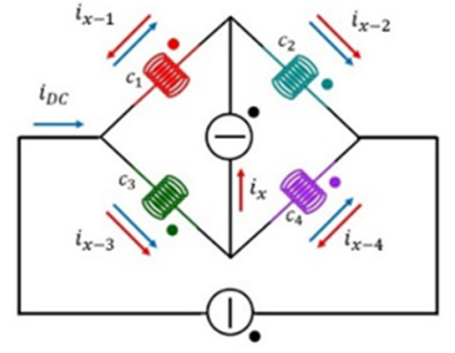

(b)
Fig. 1. (a) 2D model of the AMB (x-axis configuration) and (b) Wheatstone bridge power coil arrangement for a single axis

This winding configuration allows to generate the DC-bias field by feeding the Wheatstone bridge with a controlled DC current, shown in the bottom of Fig. 1(b) and allow to generate the required unbalance supply by introducing a current source in between the bridge itself as shown in the top of Fig. 1(b). In addition, a self-sensing bearing design can also be achieved placing windings, by means of sensing coils, on the nonwounded teeth. In such way the sensing coils are able to link the flux produced by the power winding structure and, thus, determine the position from the unbalance in the voltage across them.

The design of the AMB is carried out with Finite Element analysis combined with a first analytical design stage. From the system energy balance equation, a simplified formulation has been considered for the force generation, as shown in eq. (1)

$$
\left\{\begin{array}{c}
\mathrm{f}_{\mathrm{x}}=k_{i, x} i_{x}+k_{m, x} x \\
\mathrm{f}_{\mathrm{y}}=k_{i, y} i_{y}+k_{m, y} y
\end{array}\right.
$$

where $x$ and $y$ represent the rotor position along the AMBs geometrical axes, $i_{x}$ and $i_{y}$ are the currents injected across the arms of the Wheatstone bridge, $k_{i, x}=k_{i, y}$ are the current stiffness constants and $k_{m, x}=k_{m, y}$ are the mechanical stiffness constants, respectively for the $x$ and $y$ axis. AMBs are characterized by negative mechanical stiffness which needs to be compensated when the rotor structure in not centred. The symmetrical structure of the device leads to identical characteristic along the two geometrical axis. The currents $i_{x}$ and $i_{y}$ in eq. (1) are the differential currents which need to be imposed to modulate the DC bias current and enable the modulation of the magnetic field required to generate the forces. The geometrical structure, the DC bias current and the differential current level have been determined in order to ensure the required output force without occurring in saturation level that degrades the performance of the AMBs. FEA has been performed to validate the design and characterize the behaviour of the AMBs considered in this work. Fig. 2 presents the flux distribution in the AMBs featuring centred rotor position and imposing the maximum differential current along the $x$-axis.

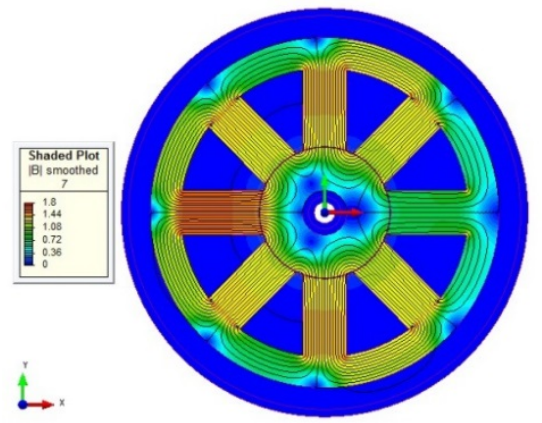

Fig. 2. Flux density distribution of the designed AMB featuring centred rotor position and maximum differential current $i_{x}$.

Due to the strong interaction of the coils with the magnetic circuit, the inductances of the coils are suitable to change in different operational conditions of the system. This is modelled and validated by means of FEA analysis, where also the saturation effect is accounted. In the following analysis a variation of $\pm 15 \%$ of the inductance with respect its nominal value is considered.

\section{POWER ELECTRONICS DRIVE DESIGN AND MODELLING}

As introduced in the previous section, the magnetic bearing system is modelled as two Wheatstone bridges, which are able to control, respectively the rotor position on the motor $x$ and $y$ axis. In order to operate properly, the system needs a DC current of $60 \mathrm{~A}$ flowing through the coils, which imposes the required flux necessary to magnetize the $\mathrm{AMB}$ and store the electromagnetic power needed for the force generation. In the ideal case, where no gravity is considered and the system is exempt from external disturbances or asymmetries, the rotor will reach a centred position in the AMB structure. A variation of $\pm 10 \%$ of the nominal current is required in order to unbalance the forces generation on the $x$ and $y$ axes and maintain the rotor in the desired equilibrium position when mechanical asymmetries and other disturbances are present. In order to fulfil these specifications, the system is controlled using three $\mathrm{H}$ Bridges (HBs) fed by a common DC bus, as shown in Fig. 3. 
The HB 1 is used to generate the DC current flowing through the WB legs while the HB 2 and 3 are able to generate the necessary leg currents unbalance, respectively on WB 1 and 2. Referring to Fig. 1(b) and Fig. 3, the system must respect the constraints defined by (2) in all the operating conditions:

$$
\left\{\begin{array}{l}
i_{x-1}=i_{x-4} \\
i_{x-2}=i_{x-3} \\
i_{y-1}=i_{y-4} \\
i_{y-2}=i_{y-3}
\end{array}\right.
$$

From eq. (2) and considering the currents dependencies in the system under study, highlighted in eq. (3),

$$
\left\{\begin{array}{c}
\mathrm{i}_{1-\mathrm{IN}}=\mathrm{i}_{\mathrm{x}-1}+\mathrm{i}_{\mathrm{x}-3}=\mathrm{i}_{\mathrm{y}-2}+\mathrm{i}_{\mathrm{y}-4} \\
\mathrm{i}_{2-\mathrm{IN}}=\mathrm{i}_{\mathrm{x}-2}-\mathrm{i}_{\mathrm{x}-1} \\
\mathrm{i}_{3-\mathrm{IN}}=\mathrm{i}_{\mathrm{y}-1}-\mathrm{i}_{\mathrm{y}-2} \\
\mathrm{i}_{1-\text { OUT }}=\mathrm{i}_{\mathrm{x}-2}+\mathrm{i}_{\mathrm{x}-4}=\mathrm{i}_{\mathrm{y}-1}+\mathrm{i}_{\mathrm{y}-3} \\
\mathrm{i}_{2-\text { OUT }}=\mathrm{i}_{\mathrm{x}-3}-\mathrm{i}_{\mathrm{x}-4} \\
\mathrm{i}_{3-\text { OUT }}=\mathrm{i}_{\mathrm{y}-4}-\mathrm{i}_{\mathrm{y}-3}
\end{array}\right.
$$

It is possible to obtain the constraints summarised in eq. (4) on the three HBs output currents.

$$
\left\{\begin{array}{l}
\mathrm{i}_{1-\mathrm{IN}}=\mathrm{i}_{1-\text { OUT }} \\
\mathrm{i}_{2-\mathrm{IN}}=\mathrm{i}_{2-\text { OUT }} \\
\mathrm{i}_{3-\mathrm{IN}}=\mathrm{i}_{3-\text { OUT }}
\end{array}\right.
$$

Under the hypothesis of symmetric branches of the WB, the system is then described as shown in (5) where $L$ and $R$ represent, respectively, the nominal winding inductance $(3.5 \mathrm{mH})$ and resistance $(0.1 \Omega)$ seen by one $\mathrm{HB}$, obtained from the FEA. Moreover, $s_{i-j}$ represents the state of the switch $Q_{i-j}$ (equal to 1 when the switch is on and 0 when the switch is off).

$$
\left\{\begin{array}{l}
{\left[\mathrm{s}_{1-1}-\mathrm{s}_{1-3}\right] \mathrm{V}_{\mathrm{DC}}=2 L\left[\frac{d \mathrm{i}_{1-\mathrm{IN}}}{d t}+\frac{d \mathrm{i}_{1-\mathrm{OUT}}}{d t}\right]+2 R\left[\mathrm{i}_{1-\mathrm{IN}}+\mathrm{i}_{1-\mathrm{OUT}}\right]} \\
{\left[\mathrm{s}_{2-1}-\mathrm{s}_{2-3}\right] \mathrm{V}_{\mathrm{DC}}=L\left[\frac{d \mathrm{i}_{2-\mathrm{IN}}}{d t}+\frac{d \mathrm{i}_{2-\mathrm{OUT}}}{d t}\right]+R\left[\mathrm{i}_{2-\mathrm{IN}}+\mathrm{i}_{2-\mathrm{OUT}}\right]} \\
{\left[\mathrm{s}_{3-1}-\mathrm{s}_{3-3}\right] \mathrm{V}_{\mathrm{DC}}=L\left[\frac{d \mathrm{i}_{3-\mathrm{IN}}}{d t}+\frac{d \mathrm{i}_{3-\mathrm{OUT}}}{d t}\right]+R\left[\mathrm{i}_{3-\mathrm{IN}}+\mathrm{i}_{3-\mathrm{OUT}}\right]}
\end{array}\right.
$$

It is important to highlight that the constraints in (4) and, as a consequence the ones in (2), have to be imposed by the converter control, independently on the three HBs. However, for control design purposes, controlling the current at the converter output represents a more practical solution, rather than directly measure the Wheatstone bridge arm currents.

Table I shows the nominal parameters of the power conversion system under exam. In order to test the designed power conversion system, variations of $\pm 12 \mathrm{~A}$ are considered on HB 2 and HB 3 while the HB 1 produce a DC current of 120A.

\section{PREDiCTIVE CONTROL FOR THE AMB SYSTEM}

In Fig. 4 the control block scheme for a single AMB is presented. The position control block considers a rotor-dynamic model of the system which calculates the required forces to be applied in order to achieve stable operative conditions. The reference forces are then evaluated from the force control block which implements the electro-magneto-mechanical model of the AMB, presented in eq. (1). Finally, the reference currents are imposed from the current control block by opportunely driving the three HB converters.

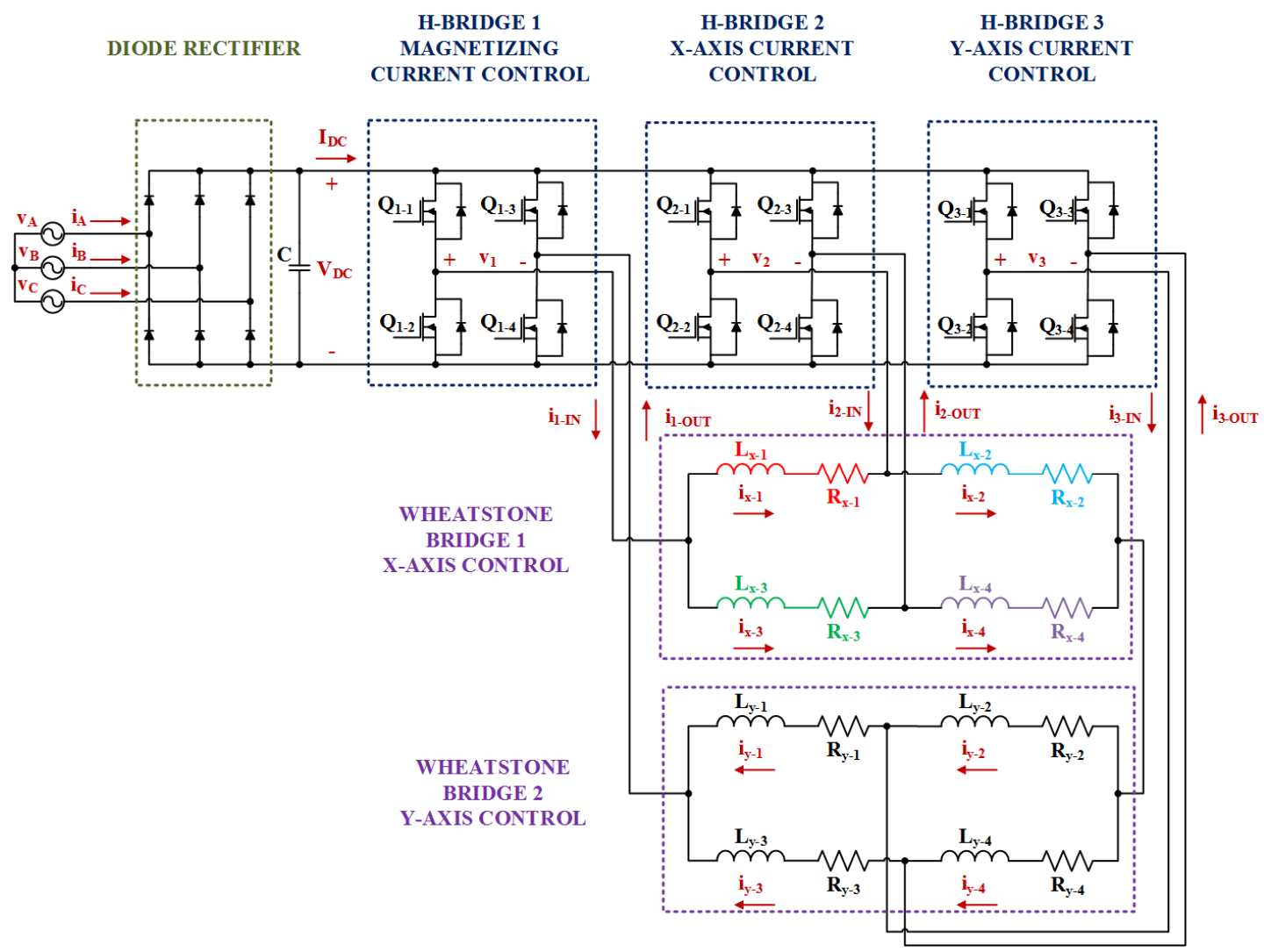

Fig. 3. Converter model and nominal parameters (colors refer to the coil arrangement shown in Fig. 1) 
TABLE I.

AMB POWER CONVERSION SYSTEM NOMINAL PARAMETERS

\begin{tabular}{|c|c|c|c|}
\hline NAME & DESCRIPTION & VALUE & UNIT \\
\hline$C$ & DC-Link capacitance & 3000 & {$[\mu \mathrm{F}]$} \\
\hline $\begin{array}{c}L_{x-1}, L_{x-2}, \\
L_{x-3}, L_{x-4}\end{array}$ & $\mathrm{x}$-axis winding inductances & 3.5 & {$[\mathrm{mH}]$} \\
\hline $\begin{array}{c}R_{x-1}, R_{x-2} \\
R_{x-3}, R_{x-4} \\
\end{array}$ & $\mathrm{x}$-axis winding resistances & 0.1 & {$[\Omega]$} \\
\hline $\begin{array}{c}L_{y-1}, L_{y-2}, \\
L_{y-3}, L_{y-4}\end{array}$ & $\mathrm{y}$-axis winding inductances & 3.5 & {$[\mathrm{mH}]$} \\
\hline $\begin{array}{c}R_{y-1}, R_{y-2} \\
R_{y-3}, R_{y-4}\end{array}$ & $\mathrm{y}$-axis winding resistances & 0.1 & {$[\Omega]$} \\
\hline$\hat{v}_{A}, \hat{v}_{B}, \hat{v}_{C}$ & Supply voltages peak value & 50 & {$[\mathrm{~V}]$} \\
\hline$V_{D C}$ & DC-Link voltage & 87 & {$[\mathrm{~V}]$} \\
\hline$i_{1-I N}, i_{1-O U T}$ & H-Bridge 1 Circulating currents & 120 & {$[\mathrm{~A}]$} \\
\hline$i_{2-I N}, i_{2-O U T}$ & H-Bridge 2 Circulating currents & \pm 12 & {$[\mathrm{~A}]$} \\
\hline$i_{3-I N}, i_{3-O U T}$ & H-Bridge 3 Circulating currents & \pm 12 & {$[\mathrm{~A}]$} \\
\hline $\begin{array}{c}i_{x-1}, i_{x-2}, i_{x-3} \\
, i_{x-4}\end{array}$ & $\mathrm{x}$-axis Wheatstone bridge currents & $60 \pm 6$ & {$[\mathrm{~A}]$} \\
\hline $\begin{array}{c}i_{y-1}, i_{y-2}, i_{y-3} \\
, i_{y-4}\end{array}$ & $\mathrm{y}$-axis Wheatstone bridge currents & $60 \pm 6$ & {$[\mathrm{~A}]$} \\
\hline
\end{tabular}

Since a high current control bandwidth is necessary to respond to any mechanical disturbance with a fast and accurate transient, a Predictive current control is implemented with a control sampling frequency of $25 \mathrm{kHz}$ for the $\mathrm{HB} 1$, which have to produce a constant DC current, and $100 \mathrm{kHz}$ for the HB 2 and 3 which, on the other hand, require a much faster control response to current reference variations. Note that the current processed by HB2 and HB3 is only a fraction of the DC bias current, and switching at higher frequencies does not increase the complexity of the conversion system.

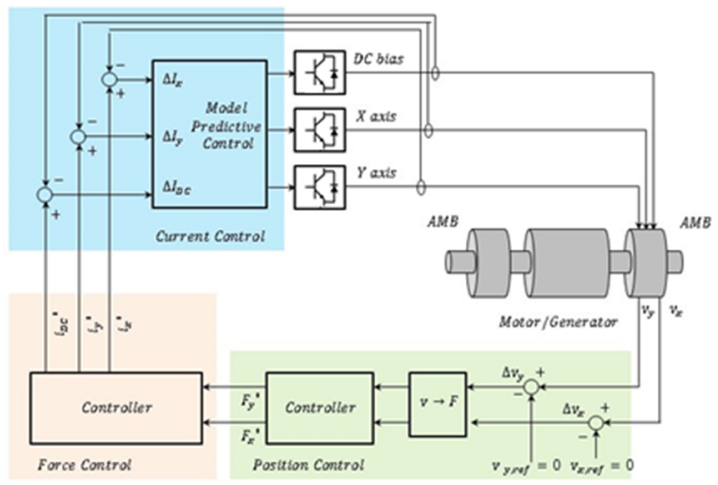

Fig. 4. Overall AMB system control scheme.

With this configuration it is possible to control the four leg currents of each WB. It is also important to highlight that, since a predictive controller is used, the converter switching frequency is variable and always lower than half of the sampling frequency, increasing the feasibility of the proposed system even when standard silicon power electronic devices are considered. On the other hand, a Predictive controller requires the online evaluation of all the possible converter states, ( 64 for the system under study) and thus demands a high computational burden. However, by taking advantage of the system symmetry, defined by equation (2), it is possible to simplify the system and reduce the number of iterations required by the Predictive controller. In fact, it is possible to divide the equations in (5), in six equations, representing the single HBs legs equations, discretized as in (6) at the sampling time $T_{s}$ and using the discrete variable $k$.

$$
\left\{\begin{array}{c}
\mathrm{i}_{1-\mathrm{IN}}(\mathrm{k}+1)=\mathrm{i}_{1-\mathrm{IN}}(\mathrm{k}) \quad+\frac{2 L}{T_{s}}\left[\mathrm{~s}_{1-1}(\mathrm{k}) \mathrm{V}_{\mathrm{DC}}-2 R \mathrm{i}_{1-\mathrm{IN}}(\mathrm{k})\right] \\
\mathrm{i}_{1-\text { OUT }}(\mathrm{k}+1)=\mathrm{i}_{1-\text { OUT }}(\mathrm{k})-\frac{2 L}{T_{s}}\left[\mathrm{~s}_{1-3}(\mathrm{k}) \mathrm{V}_{\mathrm{DC}}+2 R \mathrm{i}_{1-\mathrm{OUT}}(\mathrm{k})\right] \\
\mathrm{i}_{2-\mathrm{IN}}(\mathrm{k}+1)=\mathrm{i}_{2-\mathrm{IN}}(\mathrm{k})+\frac{L}{T_{s}}\left[\mathrm{~s}_{2-1}(\mathrm{k}) \mathrm{V}_{\mathrm{DC}}-R \mathrm{i}_{2-\mathrm{IN}}(\mathrm{k})\right] \\
\mathrm{i}_{2-\text { OUT }}(\mathrm{k}+1)=\mathrm{i}_{2-\text { OUT }}(\mathrm{k})-\frac{L}{T_{s}}\left[\mathrm{~s}_{2-3}(\mathrm{k}) \mathrm{V}_{\mathrm{DC}}+R \mathrm{i}_{2-\text { OUT }}(\mathrm{k})\right] \\
\mathrm{i}_{3-\mathrm{IN}}(\mathrm{k}+1)=\mathrm{i}_{3-\text { IN }}(\mathrm{k})+\frac{L}{T_{s}}\left[\mathrm{~s}_{3-1}(\mathrm{k}) \mathrm{V}_{\mathrm{DC}}-R \mathrm{i}_{3-\text { IN }}(\mathrm{k})\right] \\
\mathrm{i}_{3-\text { OUT }}(\mathrm{k}+1)=\mathrm{i}_{3-\text { OUT }}(\mathrm{k})-\frac{L}{T_{s}}\left[\mathrm{~s}_{3-3}(\mathrm{k}) \mathrm{V}_{\mathrm{DC}}+R \mathrm{i}_{3-\text { OUT }}(\mathrm{k})\right]
\end{array}\right.
$$

The equations in (6) are used to calculate the HBs currents at the discrete time instant $k+1$, necessary to compensate the one sampling instant delay introduced by the digital implementation. The same equations, shifted by one sampling step ahead, are then used to calculate the current predictions at the discrete time instant $k+2$. These equations are then evaluated for every possible HB state and the converter state which minimizes the cost functions in (7) is selected to be applied in the next sampling interval.

$$
\left\{\begin{array}{c}
\mathrm{G}_{1-\mathrm{IN}}(\mathrm{k}+2)=\left|\mathrm{i}_{1-\mathrm{IN}}(\mathrm{k}+2)-\mathrm{i}_{\mathrm{DC}}{ }^{*}(\mathrm{k}+2)\right| \\
\mathrm{G}_{1-\text { OUT }}(\mathrm{k}+2)=\left|\mathrm{i}_{1-\text { OUT }}(\mathrm{k}+2)-\mathrm{i}_{\mathrm{DC}}{ }^{*}(\mathrm{k}+2)\right| \\
\mathrm{G}_{2-\mathrm{IN}}(\mathrm{k}+2)=\left|\mathrm{i}_{2-\mathrm{IN}}(\mathrm{k}+2)-\mathrm{i}_{\mathrm{x}}{ }^{*}(\mathrm{k}+2)\right| \\
\mathrm{G}_{2-\text { OUT }}(\mathrm{k}+2)=\left|\mathrm{i}_{2-\text { OUT }}(\mathrm{k}+2)-\mathrm{i}_{\mathrm{x}}{ }^{*}(\mathrm{k}+2)\right| \\
\mathrm{G}_{3-\mathrm{IN}}(\mathrm{k}+2)=\left|\mathrm{i}_{3-\mathrm{IN}}(\mathrm{k}+2)-\mathrm{i}_{\mathrm{y}}{ }^{*}(\mathrm{k}+2)\right| \\
\mathrm{G}_{3 \text {-OUT }}(\mathrm{k}+2)=\left|\mathrm{i}_{3-\text { OUT }}(\mathrm{k}+2)-\mathrm{i}_{\mathrm{y}}{ }^{*}(\mathrm{k}+2)\right|
\end{array}\right.
$$

The cost functions in (7) represent the tracking errors for each converter leg, where $i_{D C}{ }^{*}, i_{x}{ }^{*}$ and $i_{y}{ }^{*}$ are the current references for the HB 1, 2 and 3 respectively. It is important to highlight that, since the input and output current of each $\mathrm{HB}$ are controlled to minimize the error with respect the same current reference, implementing (7) inherently minimize the cost functions in (8).

$$
\left\{\begin{array}{l}
\mathrm{G}_{1-\text { BAL }}(\mathrm{k}+2)=\left|\mathrm{i}_{1-\mathrm{IN}}(\mathrm{k}+2)-\mathrm{i}_{1-\text { OUT }}(\mathrm{k}+2)\right| \\
\mathrm{G}_{2-\text { BAL }}(\mathrm{k}+2)=\left|\mathrm{i}_{2-\mathrm{N}}(\mathrm{k}+2)-\mathrm{i}_{2-\text { OUT }}(\mathrm{k}+2)\right| \\
\mathrm{G}_{3-\text { BAL }}(\mathrm{k}+2)=\left|\mathrm{i}_{3-\mathrm{IN}}(\mathrm{k}+2)-\mathrm{i}_{3-\text { OUT }}(\mathrm{k}+2)\right|
\end{array}\right.
$$

The cost functions in (8) represents the unbalance on each $\mathrm{HB}$ currents. It can demonstrated that if the cost functions in (8) are kept equal to zero there is no current circulation through the three HBs (i.e. equations (2) and (3) are satisfied) and they can be considered as three independent converters, as if they are connected to three separate DC-Links.

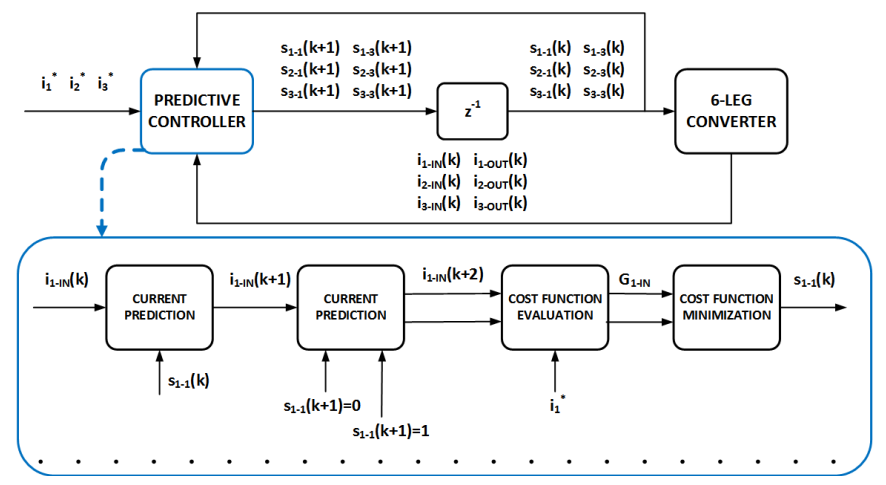

Fig. 5. Independent leg predictive current control block diagram. 
By using this approach the predictive controller has to evaluate only 12 possible converter states, thus reducing the computational power required from the practical implementation. Fig. 5 shows the control block diagram, where the control of the first leg of HB 1 is highlighted.

\section{SIMULATION RESULTS}

Simulations of the proposed system are carried out for two study cases using MATLAB/PLECS. The first simulation considers the ideal case of balanced inductances on the WB arms and the results are shown in Fig. 6. In this figure it can be noted that the DC-Link is maintained constant as expected and the three HBs generate, respectively, the necessary DC current flowing through the HB 1 and a variable square wave current with a fundamental frequency of $300 \mathrm{~Hz}$ on the HB 2 and 3 . The square wave can be seen as an example of a possible response of the outer position loop to external disturbances on the main shaft. It is important to highlight that, since the constraint in (3) is satisfied the WB leg currents follow the expected pattern, fulfilling the constraint in (2).

Fig.7 shows the simulation results for unbalanced inductances on the WB arms. This test case is particularly important since the coil inductance vary with the rotor position. In this case the control is still able to track the input and output currents of the three HBs fulfilling the constraint in (3). However, the unbalance in the arm inductance values generate an unbalance in the WB leg currents of approximately $1 \mathrm{~A}$ in the worst case, for a maximum inductance variation of $20 \%$ the nominal value. This case represent an extreme situation since variation of about $15 \%$ the nominal value are expected in the real system. Moreover, this effect can be reduced by actively mapping the value of inductance at different rotor position in the control system by using Finite Element simulation results or relying on the outer position control loop. On the other hand, this test demonstrate the stability of the proposed Predictive current control with respect to model parameters uncertainties.

\section{CONCLUSIONS}

A Predictive current control is applied to the power electronic converter control for an active magnetic bearing system, modelled as two Wheatstone Bridges. The converter is composed by three H-Bridges, which work independently and control the DC current flowing through the WBs and the current unbalances in the two WBs leg currents respectively. In fact the DC current is necessary to magnetically load the AMBs and by unbalancing the WBs leg currents is possible to shift the rotor on $x$ or $y$ machine axis in order to actively respond to mechanical vibration and other disturbances. As these vibrations, for the specific application, are in the order of hundreds of $\mathrm{Hz}$, the current control has to be able to track current variations at the same frequency. Simulation results show fast current tracking response even in case of unbalanced WB inductance values. However, in this case an offset between the WB leg currents is present. This effect can be reduced by including the knowledge of the variation of the inductance values with the rotor position.

\section{ACKNOLEDGMENT}

The research leading to these results has received funding from the European Union's Seventh Framework Programme (FP7/2009-2018) Clean Sky Joint Technology Initiative. See www.cleansky.eu.
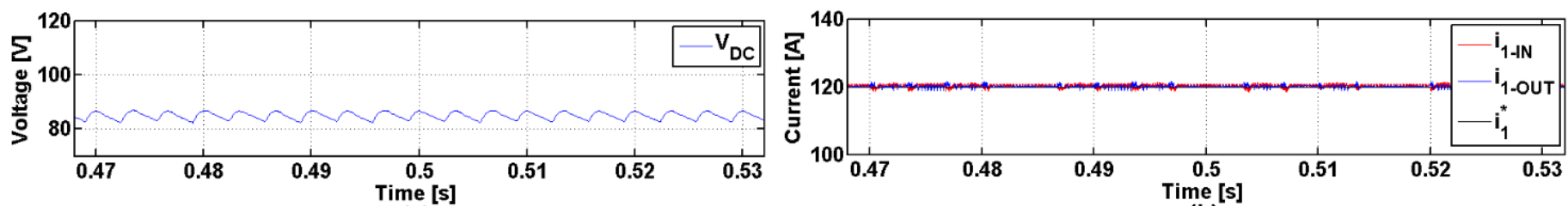

(a)
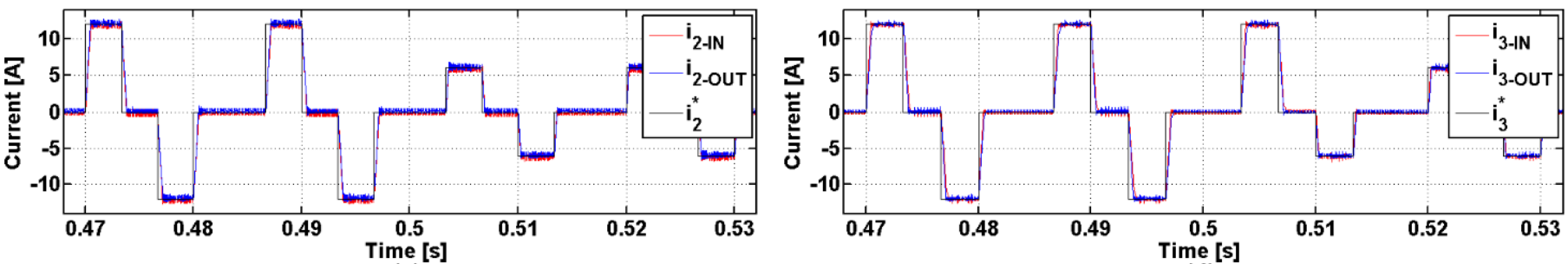

(c)
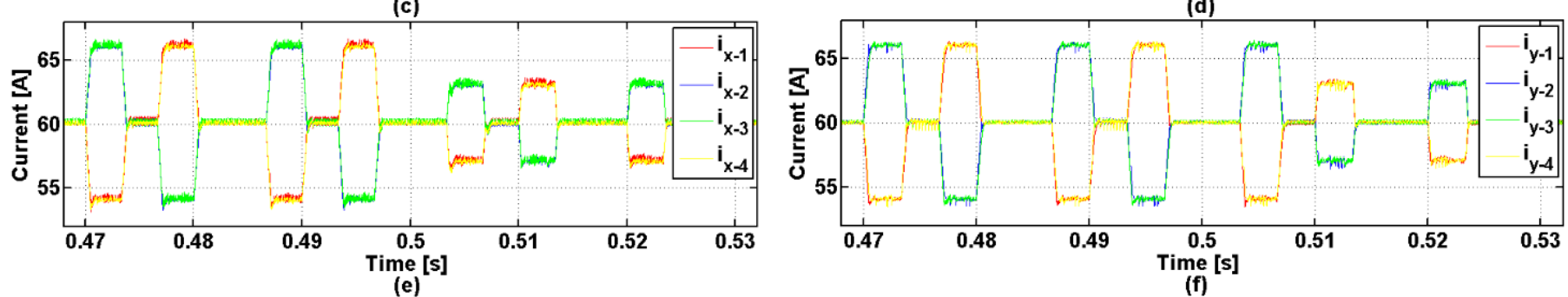

(e)

$$
L_{x-1}=L_{y-1}=L_{x-2}=L_{y-2}=L_{x-3}=L_{y-3}=L_{x-4}=L_{y-4}=3.5 \mathrm{mH}
$$

Fig. 6. Simulation results with balanced inductances: (a) DC-Link voltage; (b) Current HB 1; (c) Current HB 2; (d) Current HB 3; (e) X-axis leg currents; (f) Yaxis leg currents. 


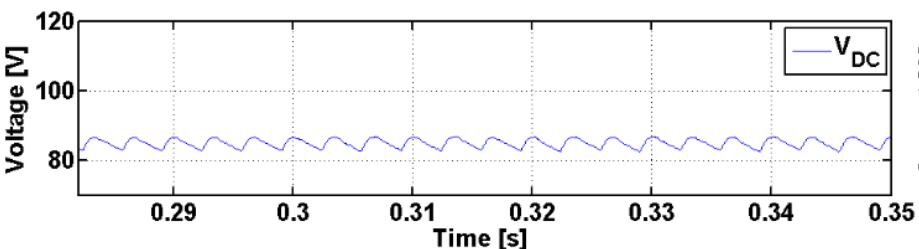

(a)

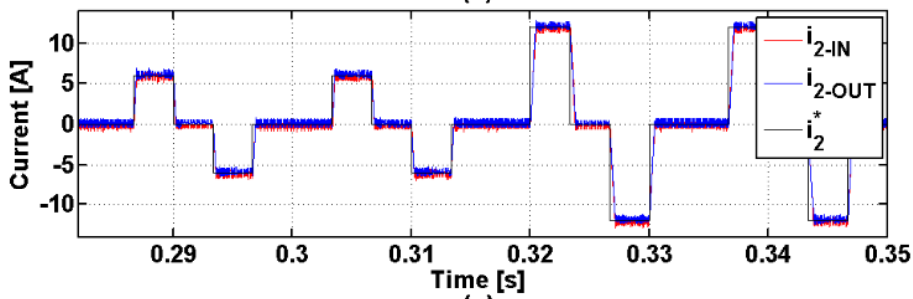

(c)

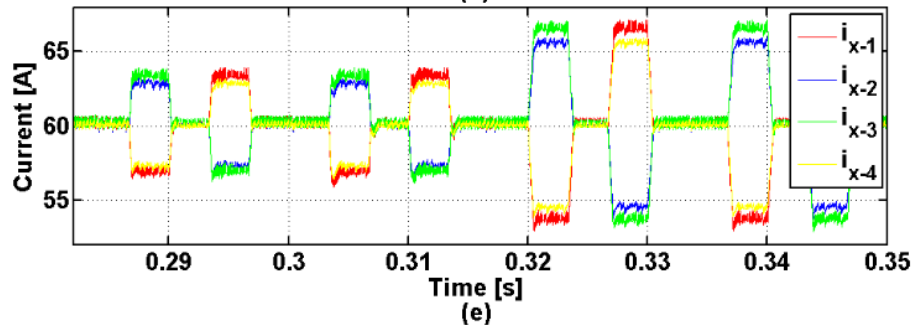

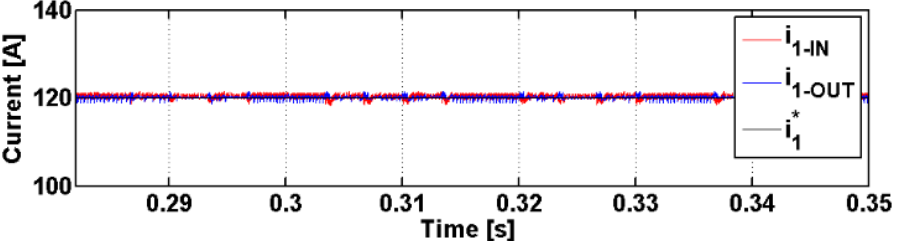

(b)



(d)

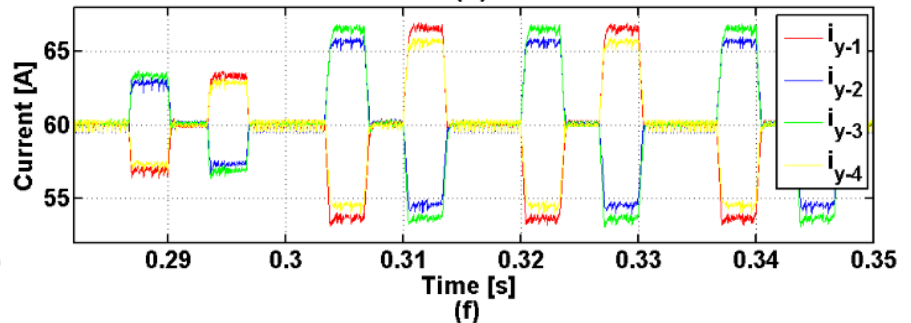

$L_{x-1}=L_{y-1}=3 \mathrm{mH}, L_{x-2}=L_{y-2}=3.2 \mathrm{mH}, L_{x-3}=L_{y-3}=3.5 \mathrm{mH}, L_{x-4}=L_{y-4}=3.7 \mathrm{mH}$

Fig. 7. Simulation results with unbalanced inductances : (a) DC-Link voltage; (b) Current HB 1; (c) Current HB 2; $\quad$ (d) Current HB 3; (e) X-axis leg currents; (f) Y-axis leg currents.

\section{REFERENCES}

[1] G. Schweitzer, "Active magnetic bearings - Chances and limitations," in Proc. IFTOMM 6th Int. Conf. Rotor Dyn., 2002, pp. 1-12.

[2] P. Imoberdorf, C. Zwyssig, S. D. Round, and J. W. Kolar, "Combined Radial-Axial Magnetic Bearing for a $1 \mathrm{~kW}, 500,000 \mathrm{rpm}$ Permanent Magnet Machine," in APEC 07 - Twenty-Second Annual IEEE Applied Power Electronics Conference and Exposition, 2007, pp. 1434-1440.

[3] P. Samanta and H. Hirani, "Magnetic Bearing Configurations: Theoretical and Experimental Studies," IEEE Trans. Magn., vol. 44, no. 2, pp. 292-300, 2008.

[4] N. . Motee, M. S. . de Queiroz, Y. . Fang, and D. M. Dawson, "Active magnetic bearing control with zero steady-state power loss," in American Control Conference, 2002. Proceedings of the 2002, 2002, pp. 827-832.

[5] W. K. S. Khoo, K. Kalita, and S. D. Garvey, "Practical Implementation of the Bridge Configured Winding for Producing Controllable Transverse Forces in Electrical Machines," IEEE Trans. Magn., vol. 47, no. 6, pp. 1712-1718, 2011.

[6] M. N. Sahinkaya and A. E. Hartavi, "Variable bias current in magnetic bearings for energy optimization," IEEE Trans. Magn., vol. 43, no. 3 , pp. 1052-1060, 2007.

[7] T. Schuhmann, W. Hofmann, and R. Werner, "Improving operational performance of active magnetic bearings using Kalman filter and state feedback control," IEEE Trans. Ind. Electron., vol. 59, no. 2, pp. 821$829,2012$.

[8] G. R. Duan, Wu Zhan-Yuan, C. Bingham, and D. Howe, "Robust magnetic bearing control using stabilizing dynamical compensators," IEEE Trans. Ind. Appl., vol. 36, no. 6, pp. 1654-1660, 2000.

[9] S. Bifaretti, P. Zanchetta, A. J. Watson, L. Tarisciotti, and J. C. Clare, "Predictive control for universal and flexible power management," in IEEE Energy Conversion Congress and Exposition (ECCE), 2010, pp. $3847-3854$.

[10] L. Tarisciotti, P. Zanchetta, A. Watson, J. C. Clare, S. Member, M. Degano, and S. Bifaretti, "Modulated Model Predictive Control for a Three-Phase Active Rectifier," IEEE Trans. Ind. Appl., vol. 51, no. 2, pp. 1610-1620, 2015.

[11] L. Tarisciotti, P. Zanchetta, A. Watson, P. Wheeler, J. C. Clare, and S. Bifaretti, "Multiobjective Modulated Model Predictive Control for a Multilevel Solid-State Transformer," IEEE Trans. Ind. Appl., vol. 51, no. 5, pp. 4051-4060, 2015.
[12] S. Kouro, P. Cortés, R. Vargas, U. Ammann, and J. Rodríguez, "Model predictive control-A simple and powerful method to control power converters," IEEE Trans. Ind. Electron., vol. 56, no. 6, pp. 1826-1838, 2009.

[13] J. Rodriguez, P. Cortes, R. Kennel, and M. P. Kazrnierkowski, "Model predictive control - a simple and powerful method to control power converters," in IEEE 6th International Conference In Power Electronics and Motion Control (IPEMC), 2009, pp. 41-49.

[14] P. Cortés, G. Ortiz, J. I. Yuz, J. Rodríguez, S. Vazquez, and L. G. Franquelo, "Model predictive control of an inverter with output LC filter for UPS applications," IEEE Trans. Ind. Electron., vol. 56, no. 6, pp. $1875-1883,2009$.

[15] L. Tarisciotti, P. Zanchetta, A. J. Watson, J. C. Clare, M. Degano, and S. Bifaretti, "Modulated Model Predictve Control (M2PC) for a 3Phase Active Front-End," in IEEE Energy Conversion Congress and Exposition (ECCE), 2013, pp. 1062-1069.

[16] L. Tarisciotti, P. Zanchetta, A. J. Watson, J. C. Clare, and S. Bifaretti, "A comparison between Dead-Beat and Predictive control for a 7-Level Back-To-Back Cascaded H-Bridge under fault conditions," in IEEE Energy Conversion Congress and Exposition (ECCE), 2013, pp. 2147 2154.

[17] R. Vargas, J. Rodríguez, U. Ammann, and P. W. Wheeler, "Predictive Current Control of an Induction Machine Fed by a Matrix Converter With Reactive Power Control," IEEE Trans. Ind. Electron., vol. 55, no. 12, pp. 4362-4371, 2008.

[18] S. Müller, U. Ammann, and S. Rees, "New Time-Discrete Modulation Scheme for Matrix Converters," IEEE Trans. Ind. Electron., vol. 52, no. 6, pp. 1607-1615, 2005.

[19] P. Cortés, J. Rodríguez, P. Antoniewicz, and M. P. Kazmierkowski, "Direct Power Control of an AFE Using Predictive Control," IEEE Trans. Power Electron., vol. 23, no. 5, pp. 2516-2523, 2008.

[20] H. Miranda, P. Cortés, J. I. Yuz, and J. Rodríguez, "Predictive Torque Control of Induction Machines Based on State-Space Models," IEEE Trans. Ind. Electron., vol. 56, no. 6, pp. 1916-1924, 2009.

[21] T. Geyer, G. Papafotiou, and M. Morari, "Model Predictive Direct Torque Control-Part I: Concept, Algorithm, and Analysis," IEEE Trans. Ind. Electron., vol. 56, no. 6, pp. 1894-1905, Jun. 2009. 